\title{
REPRESENTAÇÕES SOCIAIS DE ACADÊMICAS DO CURSO DE PEDAGOGIA SOBRE OS ANFÍBIOS ANUROS E SUAS IMPLICAÇõES NA PRÁTICA PEDAGÓGICA
}

\author{
SOCIAL REPRESENTATIONS OF EDUCATION UNDERGRADUATE STUDENTS \\ ON ANURAN AMPHIBIANS AND THEIR IMPLICATIONS FOR TEACHING
}

DOI: http://dx.doi.org/10.23926/RPD.2526-2149.2020.v5.n1.p214-233.id573

\section{Martha Silva \\ Conceição \\ Doutoranda em Ensino de \\ Ciências e Matemática pela \\ Universidade Franciscana \\ (UFN) \\ marthasc31@gmail.com}

\section{Aline Grohe Schirmer Pigatto \\ Doutora em Ciências: \\ Botânica (UFRGS) \\ Professora do Programa de Pós-Graduação em Ensino de Ciências e Matemática da Universidade Franciscana (UFN) agspigatto@gmail.com}

Resumo: Nesta pesquisa, o objetivo foi conhecer as representações sociais construídas por acadêmicas de um curso de Pedagogia em relação aos anfíbios anuros e as implicações destas representações nas suas práticas pedagógicas. A coleta de dados foi realizada por meio da técnica de grupo focal e a Teoria das Representações Sociais utilizada como alicerce da pesquisa. Os resultados evidenciam que a temática anfíbios gera sentimentos diversos, dúvidas e fragilidades conceituais, porém, o assunto desperta interesse. Evidenciam, também, que as participantes da pesquisa construíram suas representações sociais a partir de vivências, no entanto, os professores precisam dominar os conhecimentos científicos para abordá-los com propriedade com seus alunos, desenvolvendo a curiosidade, a criticidade e o interesse, além de possibilitar que os conhecimentos do universo consensual que os alunos apresentam, possam ser reconstruídos.

Palavras-chave: Anuros; universo consensual; ensino de Ciências.

\begin{abstract}
The aim of this study was to identify the social representations of Education undergraduate students on anuran amphibians and their implications for teaching. Data were collected using focus groups and the analysis was based on the framework of the Theory of Social Representations. The results show that the amphibian theme generates different feelings, doubts and conceptual weaknesses, however, the subject arouses interest. Also, that social representations are constructed from experiences; however, teachers need to master scientific knowledge in order to successfully approach it towards the students' learning, thus developing their curiosity, criticism and interest. By doing so, they would allow students to recreate their knowledge of the consensual universe.
\end{abstract}

Keywords: Anurans; consensual universe; science teaching. 


\section{INTRODUÇÃO}

Cada professor possui uma história de vida única, com experiências, culturas e saberes diferenciados. Por isso, é relevante estudar os pensamentos que eles possuem sobre um determinado assunto para compreender a sua origem e como e por que esses pensamentos foram influenciados e construídos.

De acordo com Linsingen e Leyser (2005):

A criança presta muita atenção no que o adulto faz, até mais do que no que ele diz. Não são à toa aqueles enervantes "testes" que os pequenos fazem conosco; eles estão querendo ver se nós nos manteremos no que estamos pregando, se acreditamos no que estamos dizendo (p. 6).

O professor é um profissional que possui uma responsabilidade relevante na sociedade e é por meio dele que muitos estudantes constroem seus conhecimentos, para repassá-los de geração em geração, podendo transformar o mundo em alguns anos.

Os estudos sobre representações sociais de anfíbios são escassos. Conhecer as representações sociais de pessoas sobre este grupo de animais é relevante para entender essas representações e conseguir formular melhores estratégias para conservação desses animais, visto que são o grupo de vertebrados mais ameaçados (cerca de 30\% das espécies). Nesse contexto, essa pesquisa com os acadêmicos do curso de Pedagogia se mostra de grande valor, pois é através destes profissionais que os estudantes possuem o primeiro contato com as ciências e a forma como ela é ensinada nos anos iniciais pode refletir nas suas atitudes com os animais pelo resto de suas vidas.

Assim, nesse estudo o objetivo é conhecer as representações sociais construídas por acadêmicas de um curso de Pedagogia em relação aos anfíbios anuros e as implicações destas representações nas suas práticas pedagógicas.

\section{Os ANFÍBios}

Os anfíbios são um grupo de animais que pertencem à classe Amphibia, composta por três ordens: Urodela ou Caudata, que compreende as salamandras e os tritões; Gymnophiona ou Apoda, que inclui as cobras-cegas ou cecílias, ou seja, anfíbios sem membros e, Anura, que abrange sapos, rãs e pererecas (POUGH; JANIS; HEISER, 2008).

Esses animais são considerados cosmopolitas, pois habitam os mais diversos ambientes, exceto a Antártida e os oceanos (DUELLMAN; TRUEB, 1986; GARCIA; VINCIPROVA, 2003). A maioria das espécies apresenta um ciclo de vida duplo, ou seja, uma fase larval aquática (girinos) e outra fase terrestre. Além disso, apresentam um tegumento altamente 
permeável, com dois tipos de glândulas: as mucosas, que evitam a dessecação e auxiliam na respiração cutânea e as glândulas granulosas, que produzem substâncias impalatáveis, que podem estar em todo o corpo do animal ou concentradas em regiões específicas, como as glândulas parotóides, que são bem salientes em algumas espécies, como a Rhinella schneideri (WERNER, 1894), conhecida popularmente como sapo-cururu (GARCIA; VINCIPROVA, 2003).

O Brasil apresenta a maior riqueza de anfíbios do planeta, sendo registradas 1080 espécies brasileiras: 1039 espécies de anuros, 36 espécies de cecílias e cinco espécies de salamandras (SEGALLA et al., 2016). Para o Rio Grande do Sul são registradas 92 espécies de anfíbios anuros (sendo 10 espécies ameaçadas de extinção e uma espécie exótica) e duas espécies de cecílias (HERPETOLOGIA UFRGS, 2010).

Os anfíbios são essenciais para a manutenção do equilíbrio dos ecossistemas, porém, eles estão em declínio global devido, principalmente, a ações antrópicas, como alteração, destruição e fragmentação de habitat, poluição dos recursos hídricos, contaminação por pesticidas, espécies invasoras, alterações climáticas, tráfico ilegal de animais e radiação ultravioleta, além desses, existem as doenças provocadas pelo fungo quitrídeo (SILVANO; SEGALLA, 2005; YOUNG et al. 2004; TOLEDO et al. 2006; NAVAS; OTANI, 2007; SIQUEIRA et al. 2009).

Apesar da sua importância, os anfíbios são considerados por algumas pessoas como seres nojentos, asquerosos e repulsivos. Pazinato (2013) relata que os sujeitos da pesquisa sentiram medo, repulsa e desprezo em relação aos anfíbios e afirma que esse fato pode ser devido à falta de conhecimento - o que gera diversas histórias - e também ao fato de acreditarem que esses animais são perigosos.

Oliveira e Silva-Santana (2015) relataram que alguns alunos sentem medo e nojo ao verem um anfíbio e isso se deve, muitas vezes, à cultura, mitos ou crenças populares que escutam dos familiares ou de pessoas do seu cotidiano. Pinheiro (2014) realizou um estudo com estudantes da Educação de Jovens e Adultos (EJA), em Cuiabá, e constatou que alguns alunos pensam que os sapos são estranhos, feios, nojentos, diferentes e causam nojo e medo. Alguns sujeitos (estudantes do ensino fundamental e professores) da pesquisa de Stahnke, Demenighi e Saul (2009), realizada em São Leopoldo - Rio Grande do Sul, relataram que os anfíbios são venenosos, despertam medo, nojo, aversão ou asco e que esses sentimentos são devido ao desconhecimento e a lendas populares relacionadas a estes animais. Além disso, a pesquisa de Barros et al. (2013) verificou que crianças do $4^{\circ}$ e $5^{\circ}$ ano consideravam os sapos asquerosos e 
estavam entre os animais mais temidos, além de manifestarem que sentiam medo só de ver o animal.

No estudo de Cairo, Zalba e Nebbia (2010), realizado na Argentina, foram investigadas as representações sociais de 36 professores dos anos iniciais em relação aos anfíbios. Os resultados mostraram que os professores possuem um conhecimento superficial sobre este grupo de animais e uma valoração negativa quanto a sua aparência. Por outro lado, em relação à importância utilitarista desse grupo de animais, o estudo mostrou que os professores apresentam uma valoração positiva, principalmente pelo fato de que eles se alimentam de invertebrados. Os resultados mostraram, também, que esses docentes manifestaram uma preocupação pelos problemas ambientais, tanto locais quanto globais, o que pode auxiliar em ações de educação ambiental. Os autores enfatizam que o conhecimento sobre a fauna nativa deve ser ampliado e que a população deve ser encorajada a se aproximar dos anfíbios.

\section{A TeOria das RePRESENTAÇões SOCIAIS}

A teoria das representações sociais, escrita por Serge Moscovici, foi publicada na obra La Psychanalyse, son image, son public, no início da década de 60. Essa teoria, advinda de pesquisas de Moscovici, se referia a fenômenos marcados pelo subjetivismo e os métodos da sua teoria dependiam da interpretação do pesquisador. Moscovici propôs uma psicossociologia do conhecimento, demonstrando que a realidade é socialmente construída e o saber é uma construção do sujeito (ARRUDA, 2002).

É importante ressaltar algumas características da teoria advindas do seu campo de saber, - a relação indivíduo e sociedade - como o fato de ela não surgir desligada da realidade concreta, se instalar gerando conflitos entre áreas, ocasionando dissenso, e por nem sempre ser aceita pelos padrões da ciência. Além disso, essa teoria passou por um período de latência entre as novas ideias, sua aplicação, sua visibilidade até a sua incorporação. É importante salientar também que a teoria ressalta as dimensões subjetiva, afetiva e cultural na elaboração do saber e nas ações humanas, considerando o sujeito social e o saber concreto juntamente com o seu contexto (ARRUDA, 2002). A teoria das representações sociais é essencial para a compreensão dos processos sociais, culturais e psicológicos e para o entendimento das características das práticas sociais (ABRIC, 2000).

De acordo com Moscovici (1978, apud REIGOTA, 2002, p. 12), “uma representação social é o senso comum que se tem sobre um determinado tema, onde se incluem também os preconceitos, ideologias e características específicas das atividades cotidianas (sociais e 
profissionais) das pessoas". Seguindo os preceitos de Moscovici, Denise Jodelet foi a pesquisadora que mais se aprofundou na teoria das representações sociais, sendo a sua definição de representação social a mais utilizada. Segundo a autora, "a representação social é uma forma de conhecimento socialmente elaborada e compartilhada, com um objetivo prático, e que contribui para a construção de uma realidade comum a um conjunto social" (JODELET, 2001, p. 22).

Maciel (2009, p. 17) afirma que "os estudos em representações sociais na área de educação são usados como instrumento de compreensão dos atores sociais envolvidos na prática educativa. É uma ferramenta adicional para os pesquisadores em educação". A importância desses estudos está na valorização das questões culturais, históricas e emocionais dos professores.

\section{Metodologia}

Esse trabalho é um recorte de uma pesquisa de mestrado, que teve por objetivo verificar as representações sociais construídas por acadêmicos de um curso de Pedagogia em relação aos anfíbios e as implicações na sua prática pedagógica.

Trata-se de um estudo de abordagem qualitativa, a qual, segundo Minayo (2001, p. 2122), "trabalha com o universo de significados, motivos, aspirações, crenças, valores e atitudes, o que corresponde a um espaço mais profundo das relações, dos processos e dos fenômenos que não podem ser reduzidos à operacionalização de variáveis".

O estudo foi desenvolvido com sete acadêmicas do sexto semestre do curso de Pedagogia de uma instituição de ensino privado no município de Santa Maria, região central do Rio Grande do Sul. Essas acadêmicas cursavam a disciplina de Ensino de Ciências I, sendo esse um critério de inclusão dos sujeitos na pesquisa, além do interesse em participar desse estudo.

A realização da coleta de dados ocorreu por meio da técnica do grupo focal que, de acordo com Colomé et al. (2015, p. 433), preconiza a "interação grupal e promove uma ampla problematização sobre um tema ou foco específico". O grupo focal teve dois momentos. No primeiro, norteado pela técnica de evocação livre de palavras, as participantes da pesquisa tiveram que escrever cinco palavras que lhe vinham à mente após ouvirem cada uma das cinco palavras indutoras selecionadas para a pesquisa, no caso, 'anfíbio', 'anuro', 'sapo', 'rã' e 'perereca'. Conforme Sá (1996), a evocação livre de palavras permite ao sujeito da pesquisa falar e escrever vocábulos que lhe venham à mente, após ser estimulado por uma palavra indutora que caracteriza o objeto de estudo. 
No segundo momento, as participantes tiveram a oportunidade de socializar e comentar a respeito das palavras que evocaram. Foi um momento de diálogo e socialização, com gravação e posterior transcrição das falas. Os resultados obtidos na análise das transcrições referentes ao segundo momento constituem o objeto de estudo do presente artigo. Além disso, foram analisadas as implicações destas representações na prática pedagógica das participantes da pesquisa.

\section{Resultados}

Sete estudantes participaram da pesquisa, todas do sexo feminino e com idade que variou entre 23 a 39 anos. Dentre essas, seis lecionavam em escolas, sendo que duas delas participavam do Programa Institucional de Bolsas de Iniciação à Docência (PIBID) e apenas uma acadêmica não lecionava em escola. Em relação ao ano escolar, três atuavam na educação infantil, três nos anos iniciais do ensino fundamental e uma estava na coordenação. O tempo de atuação variou, com média entre oito meses e três anos, sendo três acadêmicas com dois anos de atuação, uma com aproximadamente três anos, uma com dez meses e uma com oito meses de atuação.

Como já explicitado no item metodologia, após a técnica de evocação livre de palavras houve um momento de socialização, no qual as participantes da pesquisa tiveram a oportunidade de fazer comentários sobre as palavras que evocaram. Dessa forma, serão apresentadas e discutidas, à luz da Teoria das Representações Sociais, três situações relatadas pelas participantes, consideradas importantes no contexto dessa pesquisa, e que podem elucidar a origem das suas representações em relação aos anfíbios anuros.

\subsection{SITUAÇÃO 1 - SENTIMENTOS ENVOLVENDO OS ANFÍBIOS ANUROS}

A situação 1 se refere aos sentimentos das participantes da pesquisa em relação aos anfíbios anuros. Pode-se destacar dois sentimentos: o medo e a simpatia pelos anfíbios. O medo é um dos sentimentos mais evidenciados quando se trata do assunto anfíbios. Independente de idade, gênero, condição social, etc., os anfíbios despertam, em algumas pessoas, esse sentimento. Alguns estudos retratam como esse sentimento está presente no cotidiano, como os trabalhos de Leite (2004), Pazinato (2013), Pinheiro (2014) e Stahnke, Demenighi e Saul (2009).

Desde os momentos iniciais do grupo focal, esse sentimento já foi evidenciado, tanto em palavras evocadas, quanto nas expressões faciais, pois em vários momentos as participantes manifestaram medo e relataram experiências que explicam esse sentimento. Medo, portanto, é 
um dos elementos que pode ser considerado relevante nas Representações Sociais dos sujeitos dessa pesquisa.

Dentre os relatos, destaca-se o da participante A1.

[...] lembrei que logo que eu me mudei, lá pra minha casa, as primeiras chuvas, $[$...] eu estava sentada assim, olhando tv e dai eu olho - o piso é branco - um monte de coisinha pequenininha preta, assim. Quando eu vi, que era umas rãzinhas, meu deus eu subi [...] em cima do puff.....(risos). E agora para onde é que eu vou? [...] Corri para dentro do quarto. Quando eu olho - estou em cima da cama - olho pro chão, tinha uma dentro do quarto. Me deu um pânico [...] eu tenho isso comigo desde criança.

Nesse relato, fica claro o sentimento de medo que os anfíbios geram. A acadêmica apresenta esse sentimento desde a infância, devido ao fato de que tinha muitos animais desse grupo na sua residência, sendo que o medo persiste até hoje. A participante continuou seu relato explicando como esse sentimento se originou.

Quando eu era pequena, eu morava numa casa, que tinha muito no banheiro, elas apareciam [...] eu não sei da onde é que elas vinham. [...] Daí eu ia toma banho e sempre tinha uma lá, sempre tinha. E qualquer um da minha família que fosse no banheiro nunca tinha, mas, quando eu ia, sempre tinha. Elas ficavam bem louca pulando. Dai eu entrava e saia do banheiro e pedia para o meu pai ir lá e tirar, pra depois eu tomar banho. E, às vezes, o pai não tirava [...] Uma vez o pai disse: vou fazer tu pega na mão para ti perder o medo. Eu corria, saia gritando desesperada correndo porta a fora, deus o livre. E fiquei com isso até hoje (A1).

Nesse fragmento do relato é possível evidenciar como as vivências influenciam as Representações Sociais que os sujeitos possuem a respeito de um objeto. De acordo com Sá (2004), as Representações Sociais são produzidas pelas interações sociais presentes no cotidiano e possuem um importante papel na formação dos indivíduos. Além disso, de acordo com Arruda (2002), elas não surgem desligadas da realidade concreta, possuem dimensões subjetiva, afetiva, cultural, considerando o sujeito social e o saber concreto juntamente com o seu contexto.

Um outro aspecto interessante do relato dessa participante é o fato de que ela associa o medo com a agilidade dos anfíbios anuros. Ela relatou que sente medo de rãs e pererecas e não sente medo de sapos, pois, na sua visão, os sapos são menos agitados do que os outros anuros.

O sapo não, porque ele é quieto, se tu não mexer com ele, ele não vai mexer. Agora esse bichinho pequeno ele pula, tu tá ali ele pode pular em ti [...]Argh! E o sapo, não. Tu sai de perto do sapo e o sapo não vai te fazer nada. É menos agitado (A1).

Um outro relato interessante é o da participante A2, pois ela expressa o medo de uma maneira diferente:

Eu não tenho medo do bicho em si, do sapo, da rã ou da perereca, mas meus pais moram em Minas e eles moram para fora da cidade e assim a gente tem ambiente bem agradável, é mata, é grama, então assim quando eu vou pra casa eu encontro esses bichos. Sapinhos. E ai, a mãe [...] quando a gente era pequena, a mãe falava que a 
gente não podia deixar - quando a gente recebia roupa - a gente logo tinha que passa o ferro na roupa porque se tivesse passado um bicho desses ia deixa alguma coisa na roupa e ia pega no corpo. Ai então eu tinha medo disso, entendeu? De passar alguma coisa desse bicho para o meu corpo. Então eu tenho um certo receio. [...]quando aparece esses bichos a gente coloca neles pimenta com sal. Ai eles correm tudo (A2).

Com esse relato, é possível perceber que o medo dos anfíbios anuros está associado ao fato de que ela acredita que esses animais transmitam alguma substância para o seu corpo, simplesmente pelo fato de usar uma roupa em que o animal tenha encostado. Nesse relato, podese evidenciar o processo de ancoragem. Ancoragem é um dos processos que contribuem para a formação das Representações Sociais. Ao relatar que o medo em relação aos anfíbios está relacionado ao fato de que eles podem, de alguma forma, deixar alguma substância na roupa, a participante A2 ancora seu medo na contaminação. Além disso, foi relatado por esta participante, o uso da pimenta e do sal como recursos para afastar os anfíbios da casa, pois quando esses produtos eram colocados no corpo desses animais, eles fugiam.

Percebe-se, também, que o medo expressado pelas acadêmicas reflete fragilidades conceituais sobre o assunto. Isso porque, mesmo após anos de estudo formal, as experiências que tiveram durante a infância e as informações transmitidas pelos seus familiares ou pelas pessoas com as quais convivem se sobressaem aos conhecimentos que deveriam ter sidos construídos na escola, no processo de educação formal. A escola tem papel fundamental na consolidação da educação científica dos sujeitos, porém nem sempre isso acontece. Muitos educadores que atuam nos anos iniciais do ensino fundamental não conseguem trabalhar devidamente com as informações científicas, uma vez que suas concepções e crenças se sobressaem a elas (LIMA; MAUÉS, 2006).

Outro sentimento destacado foi a simpatia pelos anfíbios anuros. Este sentimento foi demonstrado por uma acadêmica (A4) durante a técnica de evocação livre de palavras, ocasião em que ela expressou as seguintes palavras: "bonitas", "muito bonitas" e "cores magníficas". No momento da socialização, ela relatou:

Eu coloquei que são bonitas. Até o sapo-cururu acho coisa mais linda aquele bicho [...] (A4).

É interessante pontuar que essa acadêmica apresentou uma representação social diferente das demais, pois, durante as suas falas, ela demonstrou afeição, cuidado e admiração pelos anfíbios. Ela relatou, por exemplo, que tem cuidado para manusear os animais para ambientes adequados, como pode ser visto na fala abaixo:

Ai [...] eu se eu vejo uma rã - quantas entraram às vezes lá em casa - eu arrumo uma sacolinha e pego, tiro ela, coloco lá fora para não machucar ela [...] (A4). 
Neste relato é possível perceber que essa acadêmica se preocupa em não prejudicar o animal. Esse sentimento demonstrado é pouco comum já que, geralmente, os sentimentos que os anfíbios despertam são medo, nojo, aversão e desprezo.

\subsection{SITUAÇÃO 2 - QUESTIONAMENTOS, DÚVIDAS E FRAGILIDADES CONCEITUAIS}

Outra situação a ser considerada é que as acadêmicas demonstraram ter algumas dúvidas em relação aos anfíbios. Durante a socialização, surgiram questionamentos a respeito da urina, dos venenos e das vocalizações desses animais.

Em relação à urina dos anfíbios, as acadêmicas demonstraram ter dúvidas se esses animais urinam ou não. Algumas expressaram que esses animais urinam e outras questionaram se eles realmente urinam e se essa substância é urina. Durante um diálogo, a participante A1 falou:

Eu disse que faz xixi porque quando meu pai ia pega e tira do banheiro, ela molhava né, então não sei se é xixi. E o meu pai não tinha medo ele pegava com a mão, não pegava sacola nada ele pegava com mão e atirava para fora. Daí molhava a mão dele só ele ia lá e lavava depois. Não sei se é xixi ou algum líquido que ela solta por alguma glândula.

Neste relato, percebe-se que a acadêmica tem dúvidas se é realmente urina, embora ela saiba que eles liberam alguma substância. Luchese (2013) destacou, em seu estudo, que 70\% dos alunos da zona rural e $85 \%$ da zona urbana afirmaram que os sapos urinam, que esta substância causa cobreiro e que quando entra em contato com os olhos, pode provocar cegueira. A referida autora $(2013$, p. 32) destaca que "os anfíbios costumam urinar quando se sentem ameaçados, mas essa secreção não causa cegueira, tampouco cobreiro”. De acordo com Barbosa (2007), a urina dos anuros possui a mesma composição da urina humana e, portanto, não cega. Porém, as participantes da pesquisa não relataram essa relação de cegueira ou cobreiro com a urina dos anfíbios, apenas possuíam dúvidas se esses animais realmente urinam ou se liberam alguma substância, não sabendo nomeá-la. Ademais, outra participante (A3) fez mais um questionamento:

esse sapo, tipo cururu, o sapo que a gente está acostumado a ver no nosso quintal [...] é verdade se tu pegar ele [...] vai te dar uma micose na mão ou alguma coisa?

Com base no relato da participante $\mathrm{A} 3$, percebe-se que existe dúvida se os anfíbios anuros são capazes de causar algum dano, como as micoses. Conforme mencionado anteriormente, os anfíbios não causam doenças de pele (LUCHESE, 2013). 
Em relação ao veneno presente nesses animais, algumas acadêmicas expressaram dúvidas se os anfíbios são venenosos ou não e por isso afirmaram que possuem um receio em tocá-los. Esse fato pode ser evidenciado nos seguintes relatos:

[...]vai saber se tem veneno ou não. Eu não sei direito (A4);

tenho receio se é venenoso, se mija.... essa coisa de ter o contato pele com pele. Prefiro não tocar[...] (A3);

[...]o sapo eu já ouvi falar que o veneno dele é uma glândula que ele tem nas costas né? Não sei se é (A1).

Nos relatos, fica claro que as participantes apresentam dúvidas a respeito dos venenos dos anfíbios, se eles apresentam ou não essa substância e se são prejudiciais de alguma forma. Além disso, uma das participantes ressalta que, por não ter certeza se eles apresentam veneno ou não, prefere não tocar no animal. Outra participante afirma que ela acredita que os sapos apresentam uma glândula de veneno nas costas, mas não tem certeza. Kindel, Wortmann e Souza (1997, p. 101) relatam que:

É importante destacar que estes animais não dispõem de estruturas especiais para a
inoculação deste veneno extremamente tóxico e facilmente absorvido pelas mucosas
- ele somente é liberado quando as glândulas são pressionadas por contato direto. Por
isto, é importante que se alerte os alunos sobre os riscos que a manipulação destes
seres pode lhes trazer. Novamente ressaltamos que não pretendemos substituir
atitudes de medo e repulsa pelo descuido no trato com os animais. Parece-nos que o
esclarecimento de tais questões - a existência de mecanismos de defesa próprios as
espécies e que algumas vezes implicam em problemas para as demais - também faz
parte do trabalho de aquisição de uma consciência preservacionista.

Guimarães (1997, p. 108) afirma que "é importante, portanto, que se tenha cuidado no manuseio destes animais, embora eles, com pouca frequência, tragam perigo ao homem. Como qualquer animal que possua veneno, este funciona como uma proteção contra a predação". Luchese (2013) e Souza e Souza (2005) ressaltam a importância de os professores da educação básica trabalharem a temática dos animais peçonhentos e venenosos, demonstrando a importância da preservação destes animais e, além disso, de realizarem o confronto entre os conhecimentos prévios dos seus alunos e os conhecimentos científicos, desmistificando mitos e lendas.

Nota-se que o fato de as acadêmicas desconhecerem alguns aspectos do grupo dos anfíbios gera um certo receio, pois afirmaram que preferem não tocar no animal, além disso, esse desconhecimento pode justificar o sentimento de medo. A acadêmica A1 também relatou um fato que ocorreu com o seu animal de estimação:

A minha cadela é muito medrosa, ela é bebê, o sapo estava do lado dela, eu dizia pega Meg, eu digo não pega nada, ele era todo pintado, era clarinho com umas pinta preta, eu digo vai que ele tem veneno e ela vai pegar e vai mexer e ele vai larga o veneno. 
Deixa a cadela quieta já que ela não viu. Digo toca tu com a vassoura o sapo lá para a grama né. Depois vai que ela morde dai e sei lá, pode morder, née Diz que quanto mais colorido mais venenoso, pode ser, né. Uma vez eu vi num programa de tv... mas as pererecas. Quanto menor e mais colorido, é porque ele não era de uma cor só, ele era colorido.

Nesse relato, percebe-se que novamente são demonstradas dúvidas em relação ao veneno, se os anfíbios liberam ou não essa substância e se eles possuem a capacidade de morder, manifestando medo que o anfíbio cause algum dano ao seu animal de estimação. Como já mencionado, a maioria dos anfíbios somente libera seus venenos quando suas glândulas são comprimidas, e são prejudiciais quando em contato com mucosas. De fato, os anfíbios, principalmente do gênero Rhinella, quando são mordidos, por exemplo por um cão, podem causar a morte deste animal, já que o veneno entra em contato com a mucosa, podendo causar os seguintes sintomas: congestão, hemorragia, edema pulmonar, entre outros, levando o cão a morte (SONNE et al., 2008).

Esta acadêmica relata ainda que uma vez viu, em um programa de televisão, que quanto menor e mais coloridos os anfíbios são, mais venenosos podem ser. Segundo Pough, Janis e Heiser (2008), a presença de cores nos anfíbios representa um alerta para o predador, de que esse animal apresenta substâncias impalatáveis que podem causar mal-estar. Esta é uma estratégia de defesa destes animais, denominada aposematismo ou coloração de advertência.

Outro questionamento foi em relação ao fato de os anfíbios incharem, parecendo maiores quando se sentem ameaçados.

Quando eles se sentem ameaçados, eles parecem que incham assim, né? Ficam maior, estufam (A1).

Segundo Haddad et al. (2013), o comportamento de inflar o corpo é comum entre os anfíbios anuros e trata-se de uma estratégia de defesa do animal para afastar predadores, como por exemplo o sapo-andarilho (Macrogenioglottus alipioi) (Carvalho, 1946). Além disso, o referido autor afirma que:

Além da fuga, um dos comportamentos comuns é inflar o corpo, enchendo os pulmões de ar. Esse comportamento torna o sapo maior e mais difícil de segurar como exemplificado por Macrogenioglottus alipioi. Assim, um predador, que ajustou sua investida predatória para um determinado tamanho de presa, pode desistir do ataque diante do aumento e da mudança de aspecto da presa (HADDAD et al., 2013, p. 29).

O próximo aspecto destacado é a informação que algumas acadêmicas relataram sobre a vocalização dos anfíbios anuros. Elas demonstraram conhecer que os anfíbios apresentam vocalizações únicas, e expressaram um sentimento "bom" em relação a esse aspecto, manifestando interesse e curiosidade. 
As vezes quando ta essas chuvaradas, nem deixam tu dormir, é aquela cantoria né. Mas tinha que gravar, ter um equipamento para gravar os barulhos que fazem, as vezes parecem que estão tocando até tambor de tão alto que é. [...] Diferentes sons, como que podem né? Que é vários, depende do tamanho, da espécie, não sei. [...] Se eu tivesse um aparelho bom pra gravar os sons lá de casa, eu gravava porque é uma orquestra mesmo (A4).

Neste relato, evidencia-se que o fato de os anfíbios anuros apresentarem vocalizações únicas é uma informação presente na vida desta acadêmica. Porém, ela relata desconhecer se o fato deles apresentarem vocalizações diferentes é devido a espécies diferentes ou a tamanhos diferentes. Além disso, mais uma acadêmica se manifestou a respeito das vocalizações, afirmando que:

Tanto o sapo, a rã e a perereca, cada um tem um coaxar diferente (A3).

Porém, essa acadêmica acredita que o sapo tenha uma vocalização, a rã outra e a perereca outra, mas as vocalizações variam de espécie para espécie. Quando questionadas se poderiam informar para que os anfíbios anuros cantam, algumas acadêmicas responderam: "para atrair a fêmea", "para conquistar". Segue o relato de uma acadêmica:

Eu acho que os dois cantam. Deve ter uma diferença do canto de um para outro, até para eles se comunicarem. Acho que os dois, a fêmea e o macho cantam. Se conversam né, a linguagem deles (A1).

Luchese (2013) constatou que 60\%, dos 34 alunos do ensino fundamental que participaram da sua pesquisa, sabem que os machos dos anfíbios anuros cantam para atrair as fêmeas ou conquistar as fêmeas. Kindel, Wortmann e Souza (1997) afirmam que é importante que os alunos ouçam gravações de vocalizações de anfíbios anuros e relacionem-nas com os sons do ambiente natural, sendo também interessante que os professores abordem os diferentes tipos de vocalizações produzidos por estes animais, bem como suas funções.

Nota-se que o fato de os anfíbios anuros vocalizarem gerou interesse nas acadêmicas, o que mostra que quando as pessoas conhecem mais sobre os animais, a tendência é admirá-los e respeitá-los.

Outro questionamento que surgiu foi da participante A7:

$$
\text { [...] eu vi umas gosmas brancas que tem na água, é de sapo? }
$$

Esse questionamento demonstra que a participante pode ter visto uma desova de anfíbios anuros na água, ou seja, a desova conhecida como ninho de espuma. O surgimento deste questionamento pode ter gerado um interesse a respeito da reprodução desses animais. Segundo Haddad et al (2013), os anfíbios anuros apresentam vários modos reprodutivos, geralmente os anuros da família Leptodactylidae apresentam a desova em ninhos de espuma. 


\subsection{SITUAÇÃo 3 - IMPORTÂNCIA DOS ANFÍBIOS NA VISÃO DAS PARTICIPANTES}

Outra situação a ser relatada é a importância dos anfíbios para algumas participantes da pesquisa, as quais relataram que sabem a importância destes animais, apesar de "não gostarem" deles. Esse fato pode ser percebido no relato da acadêmica A1:

Eu não gosto de sapo, nem rã e nem perereca, mas eu sei que eles comem os mosquitos né, então isso é muito importante. Por causa da dengue, por causa do Zika, né. Se ele vai comer, ele vai comer qualquer um, não vai pergunta se transmite a Zika ou não. Então é importante.

Nesse relato, nota-se que a acadêmica ressalta a importância dos anfíbios anuros em controlar insetos, principalmente os mosquitos, que são vetores de várias doenças como dengue, zika, Chikungunya, febre amarela, entre outras. Os anfíbios anuros se alimentam principalmente de invertebrados, mas também de vertebrados (BERNARDE, 2012; HADDAD et al., 2013; POUGH; JANIS; HEISER, 2008).

Outro relato interessante foi a relação entre os anfíbios e a poluição. Houve uma discordância de ideias quanto a essa questão. Enquanto uma participante defendeu a ideia de que os anfíbios vivem em ambientes não poluídos, outra acredita que vivem em ambientes poluídos.

Onde eles vivem não tem poluição (A4).

Eu discordo, porque quando tem uma sanga, ali tem sapo, rã [...] (A7).

A partir desses relatos, ficou nítida a presença de informações diferentes em relação aos anfíbios estarem em ambientes poluídos ou não. Luchese (2013, p. 7) afirma que os anfíbios são "excelentes indicadores da qualidade do habitat e ao mesmo tempo, altamente vulneráveis às modificações do mesmo", por apresentarem uma pele sensível e permeável. O fato destes animais serem indicadores de qualidade ambiental, tanto para ambientes saudáveis quanto para ambientes poluídos, é mencionado por vários autores como Santos; Lucas; Carasek (2011); Navas; Otani (2007); Young et al. (2004); Seymour, et al. (2001).

A acadêmica (A1) acrescentou que cada animal é importante para a cadeia alimentar e que na falta de um organismo ocorre um desequilíbrio ambiental, destacando que ela não possui coragem de matar os animais, apenas fugir deles ou afastá-los.

Ela faz parte de um ecossistema, da cadeia alimentar, se não tiver ela... Dai tu pensa tem uma cadeia alimentar por trás, onde sai um bicho já vai desequilibra tudo, o ecossistema vai desequilibra, vai desequilibra aquela cadeia alimentar e vira um caos. Eu enxergo assim. Por isso que eu tenho medo, mas eu não mato, eu não tenho coragem de matar, máximo que eu posso fazer é espantar para longe de mim ou correr deles. 
$\mathrm{O}$ aspecto destacado no relato anterior chamou a atenção das acadêmicas, fazendo com que elas participassem bastante da discussão. Mais uma aluna (A3) se pronunciou a respeito da importância dos animais, relatando que:

Todo bicho é importante até o mosquito.

Percebe-se, desse modo, que as acadêmicas possuem consciência de que cada animal tem um papel no ecossistema e que todos estão inter-relacionados. Ouro aspecto interessante é que quando questionadas as acadêmicas sobre o fato de os anfíbios sumirem e se isto afetaria a vida delas, apenas duas acadêmicas afirmaram que sim e acrescentaram que todo o ecossistema seria alterado.

\begin{abstract}
Ia aparece muito inseto [...] Mesma coisa se começar a aparecer muito sapo, muita rã, porque algo de errado tem. Alguma coisa de errado ta acontecendo que nem teve em uma época das abelhas que estavam sumindo [...] Acho que tudo que é demais afeta e tudo que é de menos também (A1).
\end{abstract}

Assim, fica evidente que as acadêmicas sabem da importância de cada ser vivo nos ecossistemas e têm consciência de que a falta ou o excesso de um organismo pode gerar desequilíbrios ambientais.

\title{
5.4. IMPLICAÇõeS PARA A PRÁTICA PEDAGÓGICA
}

Os resultados encontrados nesse estudo evidenciam que as participantes da pesquisa construíram representações sociais em relação aos anfíbios que refletem, de modo geral, o universo consensual. De acordo com a Teoria das Representações Sociais, o universo consensual coexiste com o universo reificado. O primeiro consiste em ideias, opiniões, crenças, preconceitos, relacionados ao senso comum. Já o segundo reflete o conhecimento produzido academicamente (ARRUDA, 2002). Destaca-se que um mesmo indivíduo pode apresentar, em relação ao mesmo aspecto, fenômeno, assunto, objeto, enfim, ideias pertencentes a ambos os universos e que as representações sociais construídas são reflexos das suas vivências e interações sociais.

No entanto, é preciso ter clareza de que o professor, no desempenho da sua prática docente, tem o compromisso de levar para os seus alunos, o conhecimento científico, além de ter plena consciência de que exercem um importante papel no processo de ensinoaprendizagem.

Segundo Chassot (2006, p. 31) "a nossa responsabilidade maior no ensinar Ciência é procurar que nossos alunos e alunas se transformem, com o ensino que fazemos, em homens e mulheres mais críticos. Sonhamos que, com o nosso fazer Educação, os estudantes possam 
tornar-se agentes de transformação - para melhor - do mundo em que vivemos". Os PCNs também destacam que "é papel da escola provocar a revisão dos conhecimentos, valorizandoos sempre e buscando enriquecê-los com informações científicas” (BRASIL, 1997, p. 35).

Conforme Arruda (2002), as representações sociais estão em constante mudança a cada interação social, a cada novo conhecimento que é construído. Assim, é essencial que o professor tenha oportunidades, tanto ao longo de sua formação inicial, como na formação continuada, de vivenciar momentos nos quais novos conhecimentos poderão ser construídos.

Delizoicov, Angotti e Pernambuco (2009, p. 34) comentam que "o trabalho docente precisa ser direcionado para a sua apropriação crítica pelos alunos, de modo que efetivamente se incorpore no universo das representações sociais e se constitua como cultura". Assim, as representações sociais dos professores precisam ser investigadas e conhecidas.

Viecheneski, Lorenzetti e Carletto (2012, p. 863) ressaltam que:

Estudos indicam que as memórias de vivências que integram a história de vida de cada professor, vão incorporando-se de modo inconsciente às suas crenças, concepções e saberes e condicionam a frequência ou a ausência dos conteúdos e atividades científicas em sala de aula, bem como as opções metodológicas adotadas.

Além disso, Viecheneski, Lorenzetti e Carletto (2012, p. 859-860) destacam que o professor precisa:

propiciar um espaço favorável à descoberta, à pergunta, à investigação científica, instigando os alunos a levantar suposições e construir conceitos sobre os fenômenos naturais, os seres vivos e as inter-relações entre o ser humano, o meio ambiente e as tecnologias.

Porém, os mesmos autores revelam que muitos professores dos anos iniciais do ensino fundamental,

... apesar de reconhecerem a importância da educação científica, não a concretizam em suas aulas porque se sentem inseguros para desenvolver um trabalho sistematizado com as crianças, em função de uma formação docente precária quanto ao embasamento conceitual para o trabalho com ciências, entre outras (VIECHENESKI; LORENZETTI; CARLETTO, 2012, p. 855).

Luchese (2013), Lima e Vasconcelos (2006) afirmam que cada vez mais novas informações e novos conceitos são gerados e que a formação inicial não é satisfatória para o desenvolvimento das práticas pedagógicas, o que torna imprescindível que os professores se atualizem, busquem formação continuada e sejam eternos aprendizes, além de não serem adeptos do comodismo, mas da descoberta, da investigação e da busca incessante do saber. Chalita (2001, p. 164-165) destaca que a formação do professor é essencial e acrescenta como importantes "não apenas a graduação universitária ou a pós-graduação, mas a formação continuada, ampla, as atualizações e os aperfeiçoamentos”. 
Com base em nossa pesquisa foi possível constatar que quando as acadêmicas tiveram oportunidade de conhecer mais sobre o grupo dos anfíbios, sanar dúvidas e questionar, elas perceberam que os sentimentos negativos que tinham em relação a esses animais poderiam se justificar pelo desconhecimento. Assim, é necessário que os professores percebam que cada ser vivo é importante para o equilíbrio dos ecossistemas, que possuem direito à vida e que sua beleza ou carisma não deveria ser o aspecto principal a ser considerado, mas o fato de que cada um deles tem o seu lugar e o seu papel no ambiente e, como tal, merecem respeito.

Diante desse contexto, é imprescindível que os professores tenham convicção em seus ensinamentos, para que os seus alunos acreditem e se sintam envolvidos no processo de ensinoaprendizagem (CHALITA, 2001).

\section{CONSIDERAÇÕES FINAIS}

A Teoria das Representações Sociais pode ser utilizada para perceber melhor as influências que o universo consensual tem na prática pedagógica. Em cada ser vivo coexistem os dois universos preconizados pela teoria. Porém, os professores, enquanto educadores, precisam se aprofundar nas temáticas abordadas, ter segurança e domínio do conteúdo a ser trabalhado, para que os alunos entendam os conhecimentos científicos e ao mesmo tempo, percebam que esses conhecimentos possuem significado, se aproximando do seu cotidiano.

Neste estudo foi abordado o tema anfíbios. Primeiro, por ser um grupo de animais aos quais temos, enquanto pesquisadores, grande estima e, segundo, por ser um grupo de animais que, embora muito presente na vida das pessoas, sofrem muitos preconceitos, uma vez que são mais conhecidos por aspectos negativos provenientes de crenças e superstições, do que pelo real e imprescindível papel no ambiente.

Os resultados mostram que a temática anfíbios gera sentimentos como medo, nojo e simpatia e que ainda existem muitas dúvidas e fragilidades conceituais, apesar de o assunto despertar o interesse das acadêmicas. $\mathrm{O}$ desconhecimento sobre este grupo de animais, no que se refere ao universo reificado, reflete a lacuna de aprendizagem que essas acadêmicas apresentam.

Os profissionais pedagogos atuam em um contexto multidisciplinar e precisam se aprofundar nos mais variados assuntos que são abordados em sala de aula. Assim, ter oportunidades de conhecer, discutir, sanar dúvidas em relação aos mais diversos temas é fundamental. Além disso, se os professores dominarem os conhecimentos científicos, poderão abordá-los com os seus alunos com mais propriedade, desenvolvendo a curiosidade, a 
criticidade e o interesse, além de possibilitar que os conhecimentos do universo consensual que os alunos apresentam, possam ser reconstruídos.

É importante destacar a necessidade de ensinar o quanto o respeito e a preservação das espécies é fundamental e que todas elas possuem direito a vida. Ademais, não deveria ser preciso argumentar sobre aspectos proveitosos ou econômicos para despertar nas pessoas o interesse pelos seres vivos, pois eles deveriam ser respeitados simplesmente pelo fato de merecerem viver.

\section{REFERÊNCIAS}

ABRIC, Jean-Claude. A abordagem estrutural das representações sociais. In: MOREIRA, Antonia Silva Paredes; OLIVEIRA, Denize Cristina de (org.). Estudos Interdisciplinares de Representação Social. Goiânia: AB, 2000, p. 27-38.

ARRUDA, Angela. Teoria das representações sociais e teorias de gênero. Cadernos de Pesquisa, São Paulo, n. 117, p. 127-147, nov. 2002.

BARBOSA, Abraão Ribeiro. Os humanos e os répteis da mata: uma abordagem etnoecológica de São José da Mata - Paraíba. 2007. 143f. Dissertação (Mestrado em Desenvolvimento e Meio Ambiente) - Programa de Pós-graduação em Meio Ambiente e Desenvolvimento PRODEMA, Universidade Federal da Paraíba, João Pessoa, 2007.

BARROS, Priscila Danielly Santos de. et al. Zoofobia: o imaginário dos alunos da educação infantil do Cabo de Santo Agostinho - PE. In: XIII JORNADA DE ENSINO, PESQUISA E EXTENSÃO - JEPEX, 13., 2013, Recife. Anais XIII Jornada de Ensino, Pesquisa e Extensão. Recife: UFRPE, 2013. p. 1-3.

BERNARDE, Paulo Sérgio. Anfíbios e Répteis: introdução ao estudo da herpetofauna brasileira. Curitiba: Anolisbooks, 2012.

BRASIL. Ministério da Educação e do Desporto. Secretaria de Educação Fundamental. Parâmetros Curriculares Nacionais: Ciências Naturais. Brasília: MEC/SEF, 1997.

CAIRO, Samanta Lis; ZALBA, Sergio MARTÍN; Nebbia, Ana Julia. Representaciones sociales acerca de los anfibios en pastizales de Argentina. Su importancia para la conservación. Interciência, Caracas, v. 35, n. 12, p. 891-896, dec. 2010.

CHALITA, Gabriel. Educação: a solução está no afeto. São Paulo: Gente, 2001.

CHASSOT, Attico. Alfabetização científica: questões e desafios para a educação. Ijuí: UNIJUÍ, 2006.

COLOMÉ, Juliana Silveira. et al. Grupo Focal como técnica de coleta e análise de dados: questões teóricas e práticas. In: LACERDA, Maria Ribeiro.; COSTENARO, Regina Gema Santini. (org.). Metodologias da pesquisa para a enfermagem e saúde. Da teoria a prática. Porto Alegre: Moriá, 2015, p. 433-450. 
DELIZOICOV, Demetrio; ANGOTTI, Jose Andre; PERNAMBUCO, Marta Maria. Ensino de Ciências: fundamentos e métodos. 3. ed. São Paulo: Cortez, 2009.

DUELLMAN, William Edward; TRUEB, Linda. Biology of Amphibians. New York: McGraw-Hill, 1986.

GARCIA, Paulo Christiano de Anchietta; VINCIPROVA, Giovanni. Anfíbios. In: MARQUES, Ana Alice Biedzicki de. et al. Livro vermelho da fauna ameaçada de extinção no Rio Grande do Sul. Porto Alegre: EDIPUCRS, 2003, p. 147-164.

GUIMARÃES, L. B. Os anfíbios. In: WORTMANN, Maria Lucia Castagna; SOUZA, Nádia Geisa Silveira de.; KINDEL, Eunice Aita Isaia. O estudo dos Vertebrados na Escola Fundamental. São Leopoldo: Editora da Universidade do Vale do Rio dos Sinos, 1997. p. 103-110.

HADDAD, Célio. F. B. et al. Guia dos Anfíbios da Mata Atlântica: diversidade e biologia. São Paulo: Anolisbooks, 2013.

HERPETOLOGIA UFRGS. 2010. Laboratório de Herpetologia da Universidade Federal do Rio Grande do Sul. Online. Versão 1.0, Novembro 2010. Disponível em: http://www.ufrgs.br/herpetologia. Acesso em 28 de janeiro de 2017.

JODELET, Denise. Representações sociais: um domínio em expansão. In: JODELET, Denise. (org.). As Representações sociais. Rio de Janeiro: EDUERJ, 2001, p. 17-44.

KINDEL, Eunice Aita Isaia. O estudo dos Vertebrados na Escola Fundamental. São Leopoldo: Editora da Universidade do Vale do Rio dos Sinos, 1997, p. 97-102.

KINDEL, Eunice Aita Isaia.; WORTMANN, Maria Lucia Castagna; SOUZA, Nádia Geisa Silveira de. Estudando os anfíbios em um ambiente urbano. In: WORTMANN, Maria Lucia Castagna; SOUZA, Nádia Geisa Silveira de.; KINDEL, Eunice Aita Isaia. O estudo dos Vertebrados na Escola Fundamental. São Leopoldo: Editora da Universidade do Vale do Rio dos Sinos, 1997. p. 97-102.

LEITE, Maria Cristina Vaz Abreu. Cobras e sapos: esses bichos malditos! Um estudo sobre a relação entre saberes populares e saberes acadêmicos na educação ambiental. 2004. 242f. Dissertação (Mestrado em Ciências da Educação) - Faculdade de Psicologia e de Ciências da Educação da Universidade do Porto, Porto, 2004.

LIMA, Maria Emilia Caixeta de Castro; MAUES, Ely. Uma releitura do papel da professora das séries iniciais no desenvolvimento e aprendizagem de ciências das crianças. Revista Ensaio, Belo Horizonte, v. 8, n. 2, p. 161-175. 2006.

LIMA, Kênio Erithon Cavalcante; VASCONCELOS, Simão Dias. Análise da metodologia de ensino de ciências nas escolas da rede municipal de Recife. Ensaio, Rio de Janeiro, v. 14, n. 52, p. 397-412, jul/set. 2006.

LINSINGEN, Luana von; LEYSER, Vivian. Feios, nojentos e perigosos: os animais e o ensino de biologia através da literatura infantil ficcional. In: V ENCONTRO NACIONAL DE PESQUISAS EM EDUCAÇÃO EM CIÊNCIAS, 5., 2005, Bauru. Atas do V Encontro 
Nacional de Pesquisas em Educação em Ciências. Bauru: ABRAPEC, 2005, p. 1-10. Disponível em: http://www.nutes.ufrj.br/abrapec/venpec/conteudo/artigos/1/pdf/p610.pdf. Acesso em: 20 fev. 2016.

LUCHESE, Mariana Scalon. A herpetologia no Ensino Fundamental: o que os alunos pensam e aprendem. 2013. 53f. Trabalho de Conclusão de Curso (Graduação do Curso de Ciências Biológicas - Licenciatura). Universidade Federal do Rio Grande do Sul, Porto Alegre, 2013.

MACIEL, Erika de Albuquerque. Representações sociais de professores e licenciandos em biologia sobre o bioma Caatinga. 2009. 117f. Dissertação (Mestrado em Ensino das Ciências) - Programa de Pós-Graduação em Ensino das Ciências, Universidade Federal Rural de Pernambuco, Recife, 2009.

MINAYO, Maria Cecília de Souza. (org.). Pesquisa Social. Teoria, método e criatividade. Petrópolis: Vozes, 2001.

NAVAS, Carlos A.; OTANI, Lye. Physiology, environmental change, and anuran conservation. Phyllomedusa, São Paulo, v. 6, n. 2, p. 83-103, dec. 2007.

OLIVEIRA, Pâmela Saionara de Freitas; SILVA-SANTANA, Cristiana de Cerqueira. Percepção de alunos do sétimo ano sobre os anfíbios em uma escola municipal no semiárido baiano, Brasil. Gestão Universitária, v. 4, p. 1-12. 2015.

PAZINATO, Daiane Maria Melo. Estudo etnoherpetológico: conhecimentos populares sobre anfíbios e répteis no município de Caçapava do Sul, Rio Grande do Sul. 2013. 66f. Monografia de especialização (Curso de especialização em Educação Ambiental). Universidade Federal de Santa Maria, Santa Maria, 2013.

PINHEIRO, Débora Dutra. "Sapiando": produto educacional para o ensino sobre anfibiofauna na modalidade da educação de jovens e adultos. 2014. 76f. Dissertação (Mestrado em Ensino de Ciências Naturais) - Programa de Pós-Graduação em Ensino de Ciências Naturais, Universidade Federal de Mato Grosso, Cuiabá, 2014.

POUGH, F. Harvey; JANIS, Christine. M.; HEISER, John B. A Vida dos Vertebrados. São Paulo: Atheneu, 2008.

REIGOTA, Marcos. Meio ambiente e representação social. São Paulo: Cortez, 2002.

SÁ, Celso Pereira. Representações sociais: o conceito e o estado atual da teoria. In: SPINK, Mary Jane. (Orgs.). $\mathbf{O}$ conhecimento no cotidiano: as representações sociais na perspectiva da psicologia social. São Paulo: Brasiliense, 2004, p. 19-45.

SÁ, Celso Pereira. Núcleo das representações sociais. Rio de Janeiro: Vozes, 1996.

SANTOS, Marina Petzen Vieira dos; LUCAS, Elaine Maria; CARASEK, Fábio Luiz. Uma análise do ensino sobre anfíbios na educação básica. Pedagógica, Revista Pedagógica, v. 2, n. 27, p. 295-312, jul/dez. 2011.

SEGALLA, Magno V. et al. Brazilian Amphibians: List of species. Herpetologia Brasileira, São Paulo, v. 5, n. 2, p. 34-46, jul. 2016. 
SEYMOUR, C. L. et al. The biogeography of the Anura of sub-equatorial Africa and the prioritization of areas for their conservation. Biodiversity and Conservation, Berlim, n. 10, p. 2045-2076, jan. 2001.

SILVANO, Débora Leite; SEGALLA, Magno. V. Conservação de anfíbios no Brasil. Megadiversidade, Belo Horizonte, v. 1, n. 1, p. 79-86, jul. 2005.

SIQUEIRA, Carla. C. et al. Density and richness of leaf litter frogs (Amphibia: Anura) of an Atlantic Rainforest area in the Serra dos Órgãos, Rio de Janeiro State, Brazil. Zoologia, Curitiba, v. 26, n. 1, p. 97-102, mar. 2009.

SONNE, Lucina. et al. Intoxicação por veneno de sapo em um canino. Ciência Rural, Santa Maria, v. 38, n. 6, p. 1787-1789, set. 2008.

SOUZA, Carlos Eduardo Pilleggi de; SOUZA, Jean Gabriel de. (Re) conhecendo os animais peçonhentos: diferentes abordagens para a compreensão da dimensão histórica, sócioambiental e cultural das ciências da natureza. In: V Encontro Nacional de Pesquisa em Educação em Ciências. Atas do V ENPEC. Bauru: ABRAPEC, 2005.

STAHNKE, Leonardo Francisco; DEMENIGHI, Janine da Silva; SAUL, Paulo Fernando de Almeida. Educação relacionada aos anfíbios e répteis: a percepção e sensibilização no município de São Leopoldo (RS). OLAM - Ciência e Tecnologia, Rio Claro, v. 9, n. 2, p. 31-63, jan/jul. 2009.

TOLEDO, Luís Felipe. et al. The occurrence of Batrachochytrium dendrobatidis in Brazil and the inclusion of 17 new cases of infection. South American Journal of Herpetology, Washington, DC, v. 1, n. 3, p. 185-191, nov. 2006.

VIECHENESKI, Juliana Pinto; LORENZETTI, Leonir.; CARLETTO, Marcia Regina. Desafios e práticas para o ensino de ciências e alfabetização científica nos anos iniciais do ensino fundamental. Atos de Pesquisa em Educação, Blumenau, v. 7, n. 3, p. 853-876, set/dez. 2012.

YOUNG, Bruce E. et al. Disappearing jewels: the status of New World amphibians. Arlington: Nature Serve, 2004.

Recebido em: 18 de novembro de 2019.

Aprovado em: 02 de abril de 2020. 